Copyright 2017 Society of Photo-Optical Instrumentation Engineers. One print or electronic copy may be made for personal use only. Systematic reproduction and distribution, duplication of any material in this paper for a fee or for commercial purposes, or modification of the content of the paper are prohibited. 


\title{
Photonic sensors: from horse racing to horse power
}

\author{
Cicero Martelli*a, Jean Carlos Cardozo da Silva ${ }^{\mathrm{a}}$, Daniel Pipa ${ }^{\mathrm{a}}$, Marco José da Silva ${ }^{\mathrm{a}}$, Carlos R. \\ Zamarreño $^{\mathrm{b}}$, John Canning ${ }^{\mathrm{c}}$, Pedro Schafauser ${ }^{\mathrm{a}}$, Guilherme Dutra ${ }^{\mathrm{a}}$, Rafael Daciuk ${ }^{\mathrm{a}}$, José R. Galvão ${ }^{\mathrm{a}}$, \\ Felipe Mezzadri ${ }^{\mathrm{a}}$, Andre B. Renzo ${ }^{\mathrm{a}}$, Uilian Dreyer ${ }^{\mathrm{a}}$, Guilherme Webber ${ }^{\mathrm{a}}$, Cesar Janeczko ${ }^{\mathrm{a}}$, Otoniel \\ G. da Rocha ${ }^{a}$ \\ ${ }^{\mathrm{a}}$ Federal University of Technology - Parana, Curitiba, PR 80.230-901 Brazil, ${ }^{\mathrm{b}}$ Electrical and \\ Electronic Engineering Department, Public University of Navarra, Pamplona, Spain, ${ }^{\mathrm{c}}$ School of \\ Computing and Communications, University of Technology Sydney, NSW 2007 Australia
}

\begin{abstract}
The use of photonic sensors to monitor horses is presented and reviewed. Results are very promising and can be used in other areas to monitor animals, machines or industrial processes.
\end{abstract}

Keywords: Photonics, sensors, optical fiber sensors, horse

\section{INTRODUCTION}

Photonic sensors are considered a very versatile technology and have being continuously evolving into mature sensing solutions that can be applied to monitor pretty much any quantity under the most challenging conditions. For example, infrared and optical detectors are used in the Mars rover to investigated the atmospheric and ground properties of the red planet, distributed temperature and acoustic sensing system are used to profile the static and dynamic physical properties of underground oil pipelines, wearable sensing clothes are coming into reality and giving people special powers to efficiently strive in harsh environments and so on. From where we stand today, it is possible to say that there is still a lot of room for improvement and evolution as the sensors get smaller and are integrated into virtually any material (metals, organic and synthetic fibers, biological tissues). Another important evolution for the photonic sensors industry is the enhancement in the interrogation capability, in terms of number of sensors per interrogator, speed and size of the interrogators as well as their robustness. On the other hand, one ought to mention the incredible development in the mobile electronic systems that can translate data from sensors (or the internet) into readily available information for users using advanced tools such as enhanced reality. Hence, this a very interesting future ahead of us when one talks about sensing solutions.

The work presented here tries to make use of this potential to demonstrate how much value can be added to an industry which traces back to the evolution of the human society, the equestrian industry. It is very well known that horses have helped man farming, transporting goods, winning wars, building cities and empires, providing food and medicines etc for centuries. And it is true that in the last 50 years their use for propulsion has declined with the evolution of self-propelled mechanical machine etc. It is very little known is that today there are over 50 million horses in the world of more than 600 breeds spanning a multibillion dollar industry. This industry is based on the potential of horses for sports, leisure, farming and food. According to American Horse Council website in the US alone "The horse industry contributes approximately $\$ 39$ billion in direct economic impact to the U.S. economy, and support 1.4 million jobs on a full-time basis. When indirect and induced spending are included, the industry's economic impact reaches \$102 billion". These numbers show the importance of the equestrian industry and of the horses for our society even today. South American has the largest population with about 15 million horses followed by Asia, 14 million, and North America, 10 million.

The potential for photonic sensors in the equestrian industry is partially demonstrated here by the use of optical fiber and infrared sensors. A drone with a high resolution camera is also used to reconstruct the movement of the horse legs. It is possible to say that the research conduct by our group indicates that most of the technology used in this work is commercially available and with some reworking it can be widely used by the equestrian industry.

*cmartelli@utfpr.edu.br; phone 554133104685 
The research work is performed under the approval of human and animal research ethics commission of the Federal University of Technology - Parana. The horses used in the tests are purebred horses of a South American breed called Criollo Horse. All experiments with the animals are performed in a farm where they live and maximum care is taken to make sure that there is no risk of injuries or accidents to animals. A veterinarian physician is always present during the tests.

The following parameters are the most commonly monitored:

i. The deformation of the hoofs during physical activity

ii. The deformation suffered by the horse shoes

iii. The balance of the horse and the symmetry of the movements

iv. The expansion and contraction of the arms, legs and neck muscles

v. The temperature of the horse in several areas of the body

vi. The impact and the vibrations caused by the horse movement over the ground

vii. The temperature image of the horse

viii. The tension in the horse bit

In order to perform such measurements several sensors are simultaneously employed. These sensors are primarily based on optical fiber Bragg grating strain and temperature sensors, distributed acoustic sensing system (DAS) which are installed in the ground where the horses exercise, infrared and optical imaging detected by a drone moving parallel to horse. Figure 1 shows one of the horses used in the experiments, the white dots represent the regions which were monitored using optical fiber sensors. A special horse shoe made of carbon fiber reinforced material with integrated optical fiber Bragg grating strain sensors was also developed and it is used in the measurements. This horse shoe consists of a very interesting tool as it can applied in real races or competitions providing the horse not only with sensing capacity but also given them a lighter and more adaptable shoe.

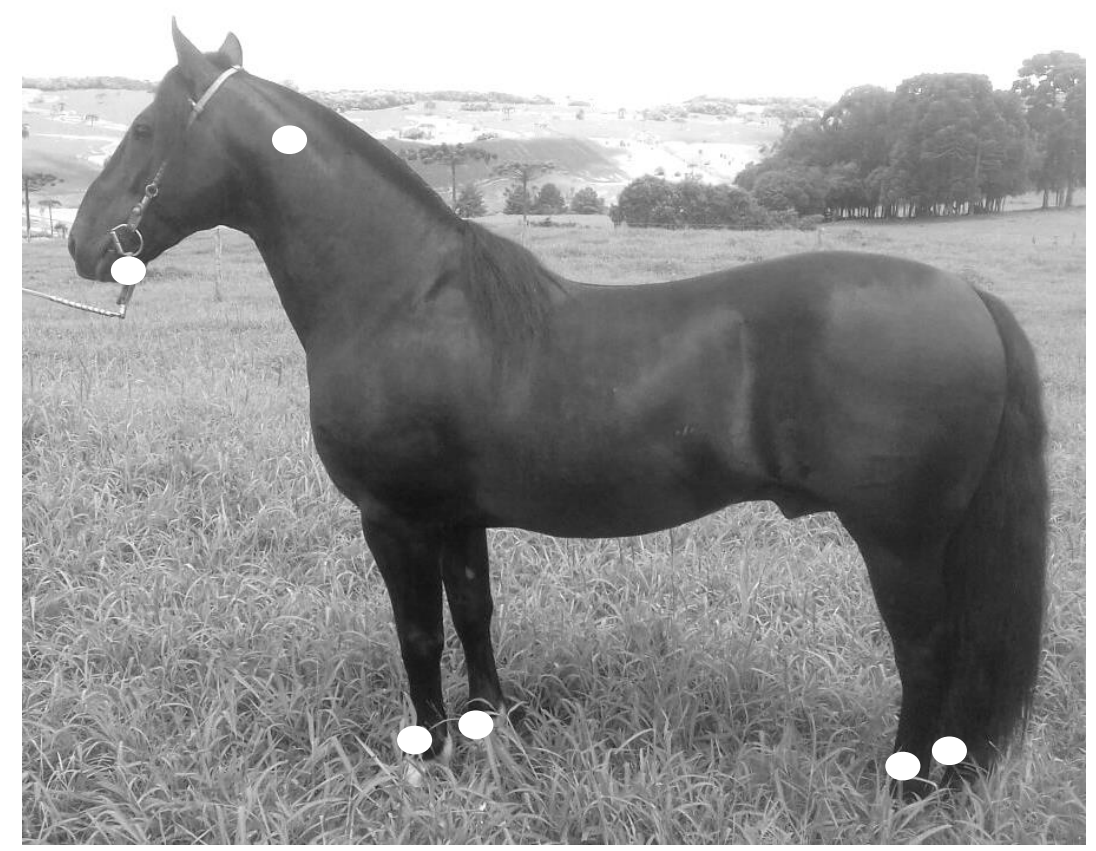

Figure 1. Image of one of the criollo horse stallions used to perform the study. 
In summary, the results that will be presented at OFS25 show some very interesting insights into the horse movement dynamics and behavior under the saddle. Weight distribution, reaction time, gait, speed are some of the information that are obtained. The sensors also provide a lot of information with respect to body dynamics of the horse with respect to balance and movement capacity with and without a rider. The measured data can help on the early diagnosis of diseases, can help riders to evaluate the evolution of training and so on. Also, the possibility of integrating the sensors directly to horse gear opens up the opportunity of providing the rider with real time information about the horse performance.

Finally, it should be noted that all the sensors and technologies used here can find a place in other applications, as introduced above. Therefore, during the presentation many examples of the application of the each specific sensor in areas such oil and energy will be given to elucidate the full potential and flexibility of the photonic sensors.

\section{REFERENCES}

[1] http://www.horsecouncil.org/. 